\title{
TESTES DE VIGOR EM SEMENTES DE SOJA (Qlyoine max (L.) MERRILL) ARMAZENADAS EM DOIS AMBIENTES
}

\section{CARLOS ALBERTO RAMÓN PFINGST CHENA}

Orientador: Dr. FRANCISCO FERRAZ DE TOLEDO

Dissertação apresentada à Escola Superior de Agricultura "Luiz de Queiroz", da Universidade de São Paulo, para obtenção do título de Mestre em Agronomia. Área de Concentração: Fitotecnia.

PIRACICABA

Estado de São Paulo - Brasil Julho - 1985 
Aos meus pais e irmãos

A minha esposa e filhos

pelo apoio constante recebido

DEDICO 


\section{AGRADECIMENTOS}

Ao Professor Francisco Ferraz de Toledo, amigo e orientador, durante o curso, em todas as fases do trabalho de dissertação e por muitas deferências recebidas ao longo do período de estudos.

Ao Professor Julio Marcos Filho, pela amizade e valiosas sugestões recebidas.

Ao Professor Dẹcio Barbin, pela anālise estatística. Aos colegas e amigos Yurika H.Komatsu, Helena M. Pescarin Chamma, Ana D.Coelho Novembre, Priscila Fratin, Antonio C. Medeiros e Edmilson W.Senedes pela ajuda e apoio constantes.

Ao Ministério da Agricultura e Pecuária do Paraguay pela concessão da bolsa de estudos.

Ao Serviço Nacional de Sementes, pela permissão outorgada.

Ao Instituto Interamericano de Cooperação para Agricultura pelas facilidades outorgadas na administração da bolsa de estudos.

A Escola Superior de Agricultura "Luiz de Queiroz" através dos Professores e funcionārios do Departamento de Agricultura e Horticultura, nossa maior gratidão.

A Elisa S.Peron pelo trabalho de datilografia. 


\section{INDICE}

\section{Página}

LISTA DE QUADROS $\ldots \ldots \ldots \ldots \ldots \ldots \ldots \ldots \ldots \ldots \ldots \ldots \ldots \ldots \ldots \ldots \ldots \ldots \ldots \ldots$

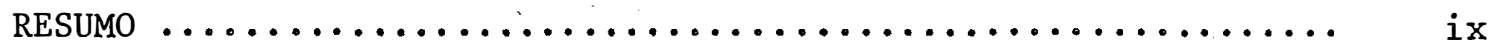

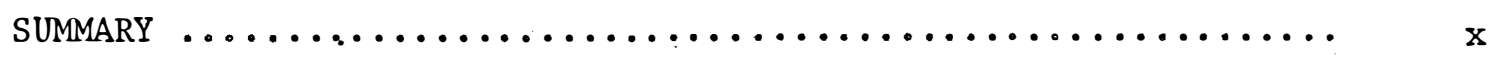

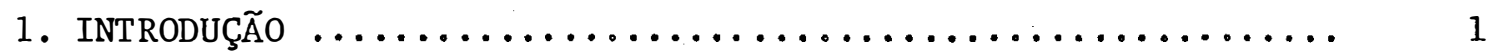

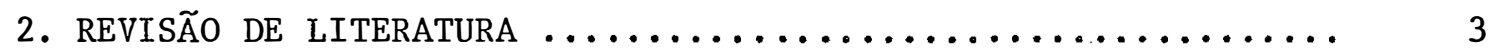

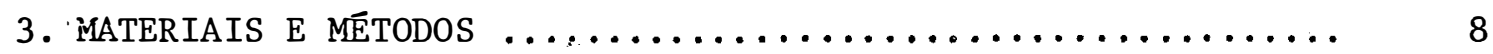

3.1. Sementes $\ldots \ldots \ldots \ldots \ldots \ldots \ldots \ldots \ldots \ldots \ldots \ldots \ldots \ldots \ldots$

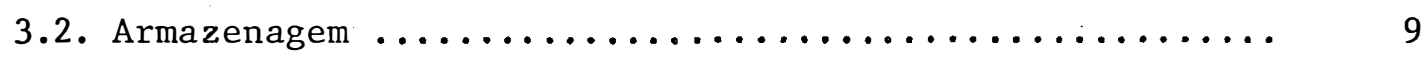

3.3. Tratamentos $\ldots \ldots \ldots \ldots \ldots \ldots \ldots \ldots \ldots \ldots \ldots \ldots \ldots \ldots$

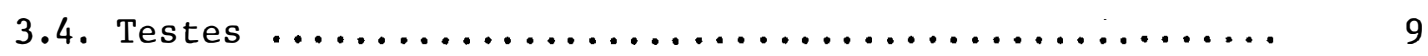

3.4.1. Teor de umidade ..................... 9

3.4.2. Germinação ....................... 10

3.4.3. Primeira contagem de germinação ........... 11

3.4.4. Engelhecimento räpido ................... 11

3.4.5. Condutividade elétrica ................. 11

3.4.6. Emergência em areia ................. 12

3.4.7. Peso de matéria seca da parte aérea das plântulas . 12

3.4.8. Comprimento da plântula e do epicotilo ....... 13

3.4.9. Emergência no campo .................. 13

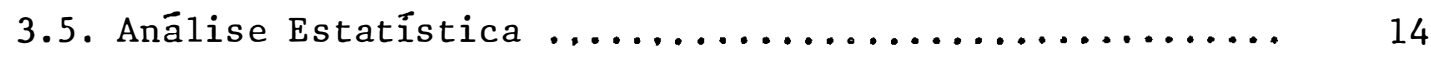

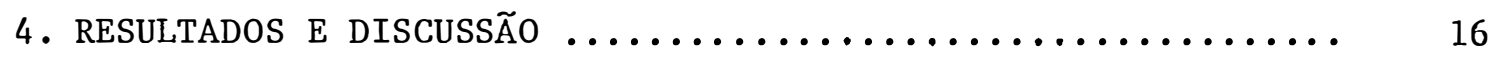

4.1. Teste de Germinação ...................... 18 
Pägina

4.2. Primeira Contagem de germinação ................ 21

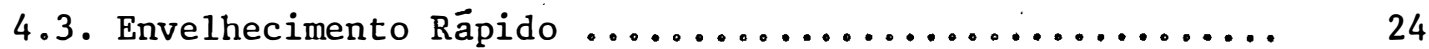

4.4. Condutividade Elétrica .................... 26

4.5. Emergência em Areia ........................ 29

4.6. Peso de Matéria Seca ....................... 31

4.7. Comprimento de Plântủla ................... 33

4.8. Comprimento de Epicotilo .................. 33

4.9. Emergência no Campo ....................... 35

4.10.Considerações Gerais ..................... 38

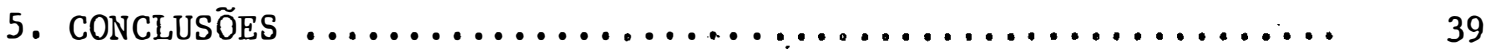

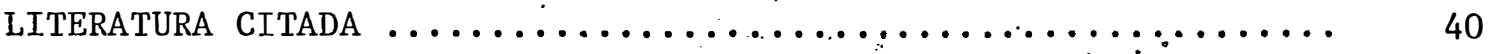

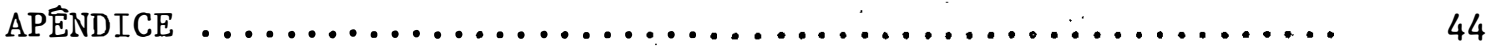




\section{LISTA DE QUADROS}

Quadro no

Pāgina

1

Tratamentos testados

2 Esquema da análise da variância dos dados colhidos

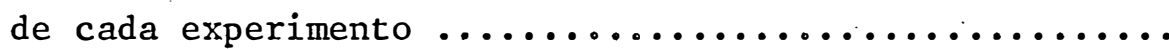

3 Valores de F significativos colhidos dos quatro ex perimentos conduzidos....................... 17

4 Germinação (dados transformados): médias observa-

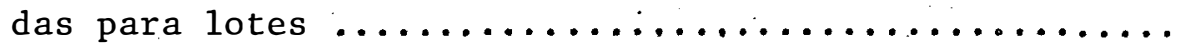

5 Germinação (dados transformados): médias observa-

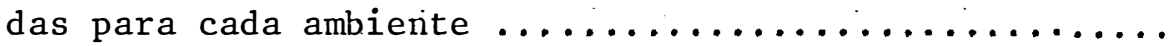

6 Primeira contagem de germinação (dados transformados): médias observadas para lotes e para intera-

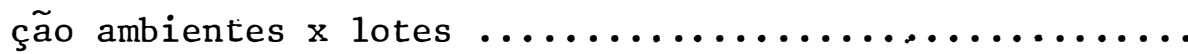

7 Primeira contagem de germinação (dados transformados): médias observadas para cada ambiente .........

8 Envelhecimento rápido (dados transformados): mēdias observadas para lotes e para interação ambien tes: $x$ lotes

9 Énvelhecimento rápido (dados transformados): mé-

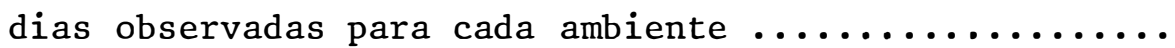


10 Condutividade elétrica (micro-mhos/grama): médias

- observadas para lotes e interação ambientes x lotes .... 28

11 Condutividade elétrica (micro-mhos/grama): médias observadas para cada ambiente ................. 28

12 Emergência em areia (dados transformados): médias observadas para lotes ..................... 30

13 Emergência em areia (dados transformados): médias observadas para cada ambiente ................ 30

14 Peso de matéria seca (miligramas/plântula: médias observadas para lotes e para interação ambientes $x$ lotes ..................................

15 Peso de matéria seca (miligramas/plântula): médias observadas para cada ambiente ................. 32

16 Comprimento de plântula (cm): médias observadas para

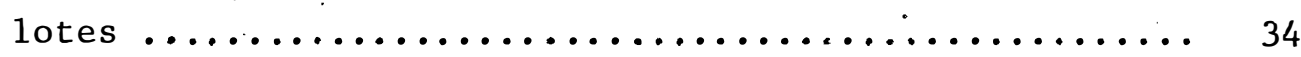

17 Comprimento de plântula (cm): médias observadas para

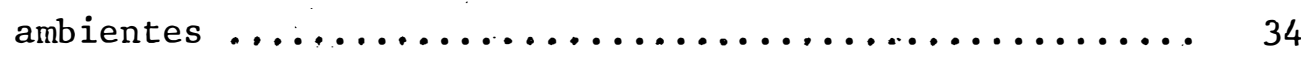

18 Comprimento de epicotilo (cm): médias observadas para lotes e para interação ambientes x lotes ......... 36

19 Comprimento de epicotilo (cm): médias observadas pa-

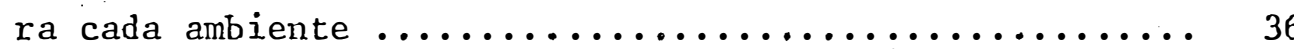


viii

Quadro no

Página

20 Emergência no campo (dados transformados): médias

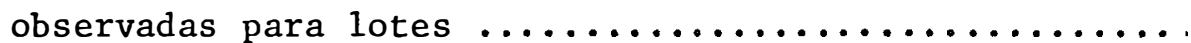

21 Emergência no campo (dados transformados): médias

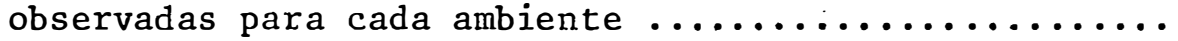




\title{
TEStes DE VIgOR EM SEMENTES DE SOJA (Glycine max (L.) Merri11) ARMAZENADAS EM DOIS AMBIENTES
}

\author{
Carlos Alberto Ramón Pfingst Chena \\ Orientador: Dr. Francisco Ferraz de Toledo
}

RESUMO

0 presente trabalho foi conduzido na Escola Superior de Agricultura "Luiz de Queiroz" com o principal objetivo de se estudar a eficiência de testes de vigor para avaliar o desempenho de lotes de sementes de soja (Glycine $\max$ (L.) Merril1) dürante a armazenagem.

Cinco lotes do cultivar IAS-5 procedentes da região de Orlandia, Estado de São Paulo, foram periodicamente submetidas aos seguintes testes: germinação, primeira contagem de germinação, envelhecimento rápido, condutividade elétrica, emergência em areia, peso de matéria seca, comprimento da plântula e do epicotilo e emergência no campo.

A anālise estatística dos dados e a interpretação dos resultados permitiram que se chegasse às seguintes conclusões: a) os testes aplicados sobre as sementes de soja não detectaram possíveis diferenças fisiológicas entre os distintos lotes; b) os lotes mostraram possuir boa qualidade e homogeneidade e as sementes armazenadas em ambiente normal apresentaram melhor desempenho que as conservadas em câmara seca. 


\section{VIGOR TESTES FOR SOYBEAN (Glycine $\max$ (L.) Merril1) SEEDS STORED IN TWO ENVIRONMENTS}

C̣ar los Alberto Ramón Pfingst Chena Adviser: Dr. Francisco Ferraz de Toledo

SUMMARY

This work was conducted in the Escola Superior de Agricultura "Luiz de Queiroz", University of São Paulo, with the main objective of studying the seed vigor testes eficiency to evaluate soybean (Glycine $\max$ (L.) Merrill) seed lots performance during storage.

Five lots of the IAS-5 cultivar, from Orlandia region, state of São Paulo; were periodically submited to the following tests: germination, first-count, accelerated aging, conductivity, sand emergency, dry matter weight, seedling lenght, epicotỵl lenght and field emergency •

The statistical analysis of data and interpretation of the results led to following conclusions: a) the imiposed tests did not detect possible. physiological differences among seed lots; b) the lots showed good quality and homogeneity and the seeds stored in normal environmental condition showed better performance than those kept in dry chamber. 
1. INTRODUÇÃO

Considerando que a soja (Glycine $\max$ (L.) Merril1) na atualidade se apresenta como uma das culturas de grande volume de produ ção e importância econômica, assume papel preponderante a produção e a comercialização de sementes de boa qualidade.

$\widehat{E}$ reconhecida, por outro lado, a sensibilidade das sementes de soja ạos fatores ambientais durante a formação e o armazenamento devido a sua estrutura morfológica e química. Assim a perda de qualidade, tanto de vigor como de germinação, que é observada com frequência, não só se atribue a condições desfavorāveís que se verificam durante o armazenamento como tambēm a sua origem, ciclo de formação(fru tificação), colheita, secagem e beneficiamento. .

Se bem que na produção de material de boa qualidade se leve em conta todos os fatores e etapas mencionados no parágrafo anterior, invariavelmente não se consegue avaliar com segurança, "a priori", o potencial de armazenamento dos lotes de sementes embora vārios 
pesquisadores tenham enfatizado a existência de um ou mais testès de laboratório ligados a esse problema.

Além disso a conservação da semente de soja nas condições de clima tropical e sub-tropical torna-se mais difícil por se acentuarem os fatores de temperaturas altas e porcentagens elevadas de umidade relativa do ar.

Tendo em vista os fatos apresentados e a necessidade de se obter mais informações sobre os testes de vigor empregados nas sementes de soja armazenadas, o presente trabalho foi planejado com os seguintes objetivos:

a. verificar entre os testes aplicados qual deles è o mais eficiente para detectar diferenças entre lotes destinados ao arma* zenamento;

b. estudar qual a relação entre alguns testes de vigor e o comportamento das sementes de soja na armazenagem. 


\section{REVISÃO DE LITERATURA}

DELOUCHE \& BASKIN (1973), estudando durante vārios anos diferentes espécies de sementes, verificaram que as respostas germinativas após o envelhecimento rápido são altamente correlacionadas com o potencial de armazenamento e que o mesmo teste além de ser de execução simples e factível para grande número de espéciès encontra-se intimamen te associado com potencial de emergência de sementes, crescimento, desenvolvimento e produtividade das plantas.

EGLI et alii (1979), procurando avaliar a relação entre os testes de vigor e o potencial de armazenamento de sementes de soja sob condições controladas de umidade $(10,5$ e 13,5\%) em câmara de ambiente controlado, trabalhando com 4 cultivares comalta porcentagem de germinação inicial, observaram que existia diferença entre o teste de germinação padrão e o vigor medido pelo teste de envelhecimento rápido; concluiram que a mudança na qualidade da semente de soja durante o armazenamento é fun ção das condições de armazenamento, conteúdo de umidade da semente e do nível 
inicial da qualidade da semente estimados pelo teste de envelhecimento rāpido.

Também USBERTI (1979), trabalhando com sementes de soja armazenadas durante 10 meses, utilizou como parâmetros para determinar potencial de armazenamento os valores do teste de germinação e de vārios períodos de envelhecimento rápido (12, 24, 36 e 60 horas) observan do que os lotes de sementes com porcentagem de germinação inicial seme1hantes, responderam diferentemente ao teste de envelhecimento rápido mostrando a ocorrência de diferenças em deterioração não detectadas pe1o teste de germinação. Desta forma seus resultados coincidiram com os de EGLI et alii (1979) com a diferença de que os lotes foram submetidos a armazenamento aberto e não sob condições controladas de umidade. Mc DONALD Jr. (1977), TAO (1979); MARCOS FILHO \& VINHA (1980)relataram que o teste de envelhecimento rápido é capaz de predizer a capacidade de conservação toda vez que ao iniciar o teste seja unifornizado o teor de umidade das sementes para evitar a possibilidade de ocorrência de efeitos mais drásticos do envelhecimento sobre as sementes mais ümidas e assim obter resultados comparāveis. Além disso, Mc DONALD Jr. (1977), no desenvolvimento do trabalho citado, verificou que as sementes de soja e cevada que continham teor de umidade mais ele vado, mostraram maior crescimento de hipocotilo e coleoptilo. Da mesma forma MARCOS FILHO et alii (1978), pesquisando com soja, observaram que as sementes do cultivar "Davis" com teor de umidade de 11,0\%, apresentaram médias de germinação significativamente superiores em relação as sementes que continham $7,0 \%$ e 9,0\% de umidade. 
Com referência a outros métodos de avaliação do vigor das sementes de soja armazenadas, EDJE \& BURRIS (1970) constataram que os testes que se mostraram eficientes para este mister foram os de primeira contagem de germinação, teste de frio e condutividade elétrica, em bora MARCOS FILHO et alii (1984) discordem no que se refere aos resultados obtidos com o teste de condutividade elétrica, pois em trabalho realizado por estes autores com sementes de soja, utilizando o teste de lixiviação de $\mathrm{K}$, não constataram este fato, tendo em conta que a lixiviação de $\mathrm{K}$ proporciona as mesmas informações fornecidas pelo teste de condutividade elétrica segundo Simon e Raja-Harum (1972) citados, por MARCOS FILHO et alii (1984).

GILL \& DELOUCHE (1973), pesquisando com milhos híbridos armazenados em diferentes ambientes, observaram que os testes de primeira contagem e taxa de crescimento de plântulas detectaram deterioração. Por outro lado a permeabilidade da membrana, medida em termos de resistência elétrica,não foi consistente porque dito teste è mais sensível a injūrias no tegumento, mudanças de temperatura, intervalo de agitação da solução, intensidade e precisão de tempo. Dado o exposto concluiram que a resistência elétrica promete ser um indicador de deterioração difícil de ser aplicado.

- TAO (1978), pesquisando o comportamento de sementes de soja submetidas ao teste de condutividade elétrica, observou que diversos são ọ fatores que podem causar variações significativas nos resultados, como a água corrente, o papel de filtro e a temperatura entre outros, acrescentando ainda, que o baixo teor de umidade $(8,8 \%$ ou 
menos) facilita o trincamento, concluindo desta forma que o teste de condutividade elétrica em soja deve ser conduzido sem filtrar, com sementes.não injuriadas e com teor de umidade de $13 \%$ ou mais.

Por outro lado BYRD \& DELOUCHE (1971) verificaram que as sementes de soja envelhecidas artificialmente e armazenadas em distintos ambientes mostraram-se sensíveis aos testes de primeira contagem de germinação, comprimento da radícula e do hipocotilo.

MARCOS FILHO et alii (1984) não citaram uma relação dire ta entre o teste de emergência e o armazenamento no trabalho que realizaram com sementes de soja no transcurso de um ano, período durante o qual as sementes se encontravam armazenadas. Utilizando vārios testes de avaliação de vigor e relacionando-os com emergência de plântulas no campo concluiram que dentre os testes de laboratório os de germinação, primeira contagem e velocidade de germinação foram os mais eficientes para identificar diferenças entre o potencial de emergência das plântulas no campo.

Embora não se tenha encontrado na literatura trabalhos de emergência em areia com saturação a $60 \%$ para avaliar o potencial de armazenamento, pode-se levar em consideração o trabalho realizado por RAZERA (1982), que pesquisando com dois cultivares de soja e realizando o téste de emergência em caixas com solo arenoso, sob diferentes temperaturas e níveis de umidade, concluiu que as condições ótimas para emergência de plântula de soja são $28^{\circ}$ a $32^{\circ} \mathrm{C}$ de temperatura e níveis de 40 a $60 \%$ de capacidade de campo. 
WETZEL (1975), visando avaliar os efeitos do tamanho sobre o vigor das sementes, utilizou entre outros os seguintes testes de vigor: primeira contagem de germinação, envelhecimento rápido, peso seco das plântulas, velocidade e porcentagem de emergência observando que todos estes métodos mostraram diferenças entre os tratamentos.

CARVALHO et alii (1977) trabalharam com soja, cultivar "Santa Rosa", procedente de São Paulo e Rio Grande do Su1, para determinar a qualidade fisiológica da mesma. No referido trabalho utilizaram uma série de parâmetros entre os quais destacaram-se significativamente a emergência total, a velocidade de emergência, o comprimento do hipocotilo e o comprimento de epicotilo. 
3. MATERIAIS E METTODOS

O presente trabalho foi conduzido no Laboratório de Sementes e no Campo Experimental do Departamento de Agricultura e Horticultura da Escola Superior de Agricultura "Luiz de Queiroz" da Universidade de São Paulo (DAH/ESALQ/USP).

\subsection{Sementes}

Para a realização desta pesquisa foram utilizadas cinco amostras de diferentes lotes de sementes fiscalizadas de soja (Glycine $\max$ (L.) Merrill), do cultivar IAS-5 da safra 1983/84, procedentes da região de Orlandia, Estado de São Paulo.

-

- Logo após a colheita, secagem, beneficiamento e amostragem, as sementes foram encaminhadas à ESALQ e armazenadas em câmara seca (35\%UR e $22^{\circ} \mathrm{C}$ ) até o início deste trabalho. 


\subsection{Armazenagem}

Por ocasião do início dos ensaios, cada amostra foi homogeneizada e dividida em duas partes, onde uma delas foi mantida em câmara seca e a outra em condições ämbientais naturais do laboratório. Desta forma as dez sub-amostras obtidas, duas de cada lote, foram armazenadas durante o período em que se realizaram os diferentes experimentos.

\subsection{Tratamentos}

Os cinco lotes e os dois ambientes de armazenamento for maram os dez tratamentos testados periodicamente de agosto de 1984 a fevereiro de 1985 (quadro 1).

\subsection{Testes}

As sementes correspondentes aos dez tratamentos foram submetidas periodicamente (dois em dois meses) aos testes conforme são apresentados a seguir.

\subsubsection{Teor de umidade}

0 teor de umidade foi determinado em estufa a $105^{\circ} \mathrm{C} \pm 3$

durante 24 horas trabalhando-se com duas repetições por sub-amostra se guindo-se as Regras para Anālise de Sementes (Brasil, M.A. 1976). 
Quadro 1. Tratamentos testados

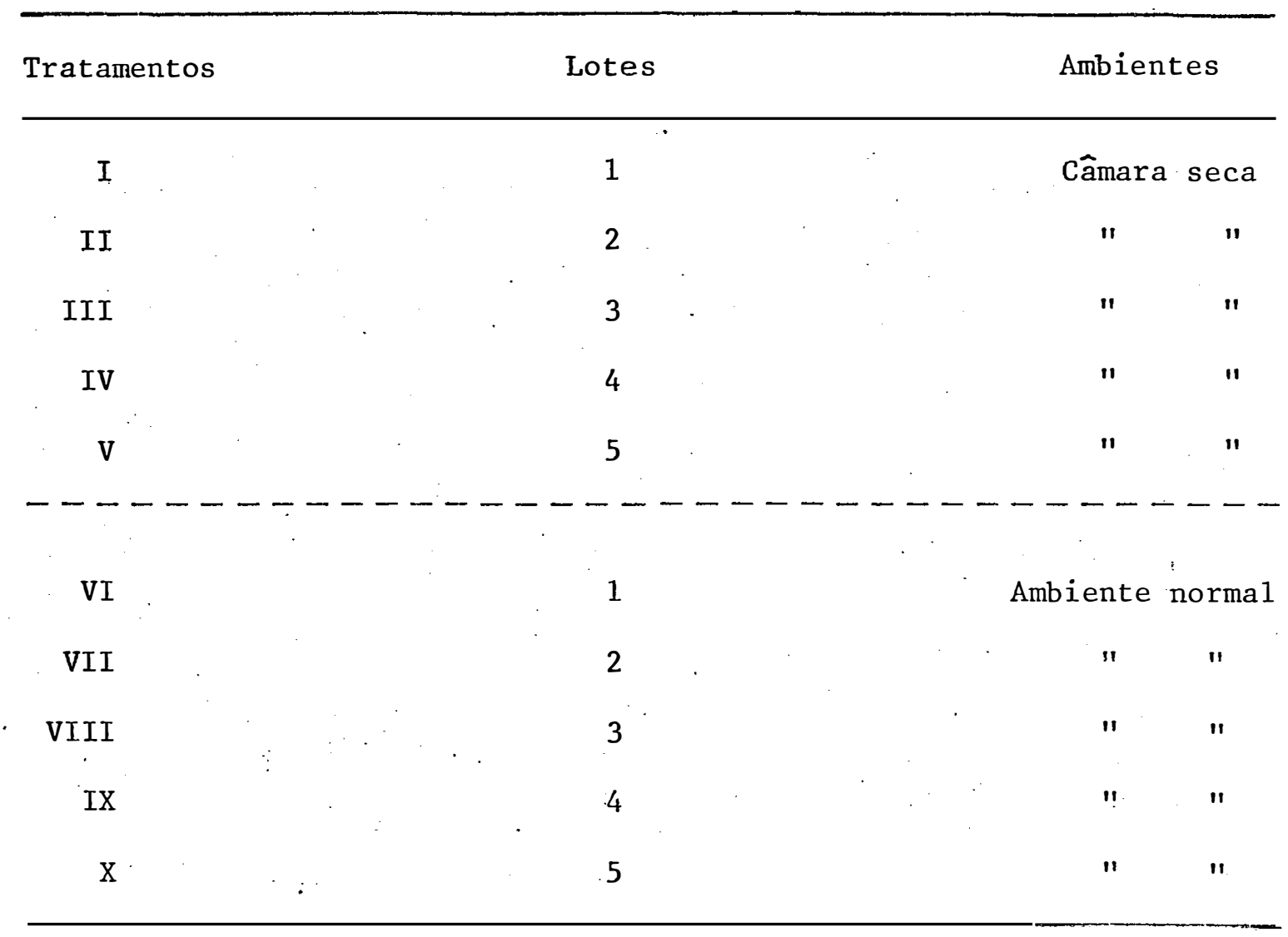

3.4.2. Germinação

0 teste de germinação foi realizado com quatro repetições de cinquenta sementes por tratamento, em germinador modelo CATI, marca Ferraz, à temperatura constante de $30^{\circ} \mathrm{C}$. Utilizou-se como substrato o papel toalha e as contagens foram efetuadas aos quatro e sete dias após a semeadura, segundo os critérios estabelecidos nas Regras para Anālise de Sementes (Brasil, M.A., 1976). 


\subsubsection{Primeira contagem de germinação}

Foi realizada conjuntamente com o teste de germinação computando-se as porcentagens de plântulas normais que foram verificadas no quarto dia após a semeadura segundo técnica adotada por BYRD e DELOUCHE (1971) .

\subsubsection{Envelhecimențo rápido}

Foram utilizadas duzentas sementes para cada tratamento que foram colocadas em recipientes de plástico (gerbox) adaptados para este teste, aos quais foram adicionados $40 \mathrm{ml}$ de água. Após tampados os recipientes foram colocados em câmara incubadora FANEM a $42^{\circ} \mathrm{C}$ de tem peratura durante 48 horas. Depois de transcorrido o tempo estabelecido, as sementes foram retiradas da incubação e colocadas para germinar durante quatro dias, conforme o teste flescrito em 3.4.2. Os resultados foram computados em porcentagens de plântulas normais (MARCOS FILHO et alii, 1980).

\subsubsection{Condutividade elétrica}

Para cada tratamento foram utilizadas quatro repetições de 25 sementes com tegumentos inteiros. (integros) que foram pesadas em balança analítica METTLER e logo colocadas em recipientes de plástico (copos), contendo $75 \mathrm{ml}$ de água destilada cada um. Foram então colocados no germinador marca STULTS SCIENTIFIC ENGR. CORP. a $20^{\circ} \mathrm{C}$ de temperatura durante 24 horas. Decorrido o tempo estabelecido a condutividade elétrica da solução de cada recipiente de plástico, previamente 
agitada, foi avaliada utilizando-se o condutivimetro DIGIMED modelo CD20 e os resultados foram expressos em micro-mhos por grama de sementes (POPINIGIS, 1977).

\subsubsection{Emergência em areia}

Para cada tratamento foram instaladas duas repetições de cinquenta sementes, as quais foram semeadas em caixas de plástico $(0,22 \times 0,33 \times 0,10 \mathrm{~m})$ contendo areia lavada seca e peneirada, na quanti dade de $2,543 \mathrm{~kg}$. Depois de realizada a semeadura procedeu-se à cobertura com a mesma quantidade de areia, que após nivelamento recebeu āgua na quantidade necessária para se obter a umidade de saturação de $60 \%$.

As caixas de plástico contendo as sementes, foram mantidas em condições ambientais de laboratório durante dez dias após os quais computou-se o número de plântulas emergidas e os resultados foram expressos em porcentagens de emergência.

3.4.7. Peso de matéria seca da parte aérea das plântulas

Juntamente com o teste de emergência em areia determinou-se o peso de matéria seça da parte aérea das plântulas. A avaliação consistiu do corte na superfície da areia das plântulas emergidas que, uma vez contadas e eliminados os cotiledones, eram colocadas em saquinhos de papel conforme cada repetição. Os saquinhos de papel contendo as plântulas foram levados à estufa a $70^{\circ} \mathrm{C}$ de temperatura durante o tempo necessário para que os pesos respectivos se mostrassem 
constantes. Em seguida, procedeu-se à pesagem da matëria seca contida em cada saquinho de papel, onde o valor do peso foi dividido pelo numero de plântulas correspondentes, obtendo-se desta forma o peso médio da matéria seca por plântula, que fọi expresso em miligramas(POPINIGIS, 1977)

3.4.8. Comprimento da plântuia e do epicotilo

Para essas determinações aproveitou-se o teste de emergência em areia como assim também as plântulas que foram cortadas para o peso de matéria seça, procedendo-se da seguinte forma:

a. para avaliar o comprimento, tomou-se ao acaso dez plântulas de cada.repetição; a determinação se realizou tomando como referência o ponto onde foi ela cortada e o ponto de inserção das fo1has primärias;

b. para determinar o comprimento do epicotilo utilizouse o mesmo material que foi usado na avaliação anterior; para a medição tomou-se como referência o ponto de inserção dos cotiledones e a inserção das folhas primärias.

Os resultados de ambas determinações foram expressos em centímetros.

\subsubsection{Emergência no campo}

O teste foi conduzido em canteiros do Departamento de Agricultura e Horticultura da ESALQ nos meses de outubro a fevereiro. 
A semeadura foi realizada com quatro repetições de cem sementes para cada tratamento, em sulcos de quatro metros de comprimento com cinco centímetros de profundidade. Cada sulco distou do outro 40 centímetros. A contagem foi realizada aos dez e vinte dias após a semeadura, tendo os resultados sido expressos em porcentagens de emergência, conforme MARCOS FILHO et alii (1984).

\subsection{Anālise Estatística}

Os testes descritos no item 3.4. foram aplicados sobre os tratamentos quatro vezes consecutivas, respeitando-se entre : estas aplicações intervalos de aproximadamente dois meses. Foram formados, então, quatro experimentos consecutivos para cada teste, salvo para emergência no campo em que se instalou somente três experimentos.

Os dados colhidos de cada experimento sofreram anảlise estatística conforme o delineamento fatorial (TOLEDO, 1981) que se acha esquematizado no quadro 2, salvo para o teste de emergência em areia, em que se utilizou somente duas repetições. Neste caso os graus de 1iberdade do resíduo seriam dez e o do total seriam dezenove.

As mêdias dos tratamentos foram comparadas entre si por meio do método de Tukey (PIMENTEL GOMES, 1982). Os dados obtidos em porcentagem foram transformados em arc sen $\sqrt{\mathrm{X} / \overline{100}}$ previamente a anā1ise. 
Quadro 2. Esquema da anālise da variância dos dados colhidos de cada experimento

Causas de Variação

Graus de Liberdade

Lotes (L)

4

;

Ambientes (A)

1

L $x A$

4

Resíduo

30

TOTAL

39 
4. RESULTADOS E DISCUSSÃO

0 presente trabalho foi realizado com os objetivos de se estudar qual é a relação entre vários testes de vigor è o comportamento de sementes de soja durante o armazenamento e verificar qual deles é o mais eficiente para apontar diferenças principalnente entre lotes.

Os dados colhidos dos experimentos foram analisados es$i$ tatisticamente conforme modelos encontrados na literatura e as médias estatisticamente diferentes foram comparadas por meio do teste de $\mathrm{Tu}-$ key.

No quadro 3 são apresentados os valores significativos de F para cada teste conduzido nos quatro experimentos.

Pode-se verificar por meio desse quadro que não houve uma resposta consistente aos testes usados ao longo dos experimentos executados. Assim, por exemplo, os testes de germinação e primeira contagem não acusaram diferenças significativas ao níve1 de $1 \%$ de probabilidade entre lotes de sementes no primeiro, terceiro e quarto experimentos, porém acusaram no 


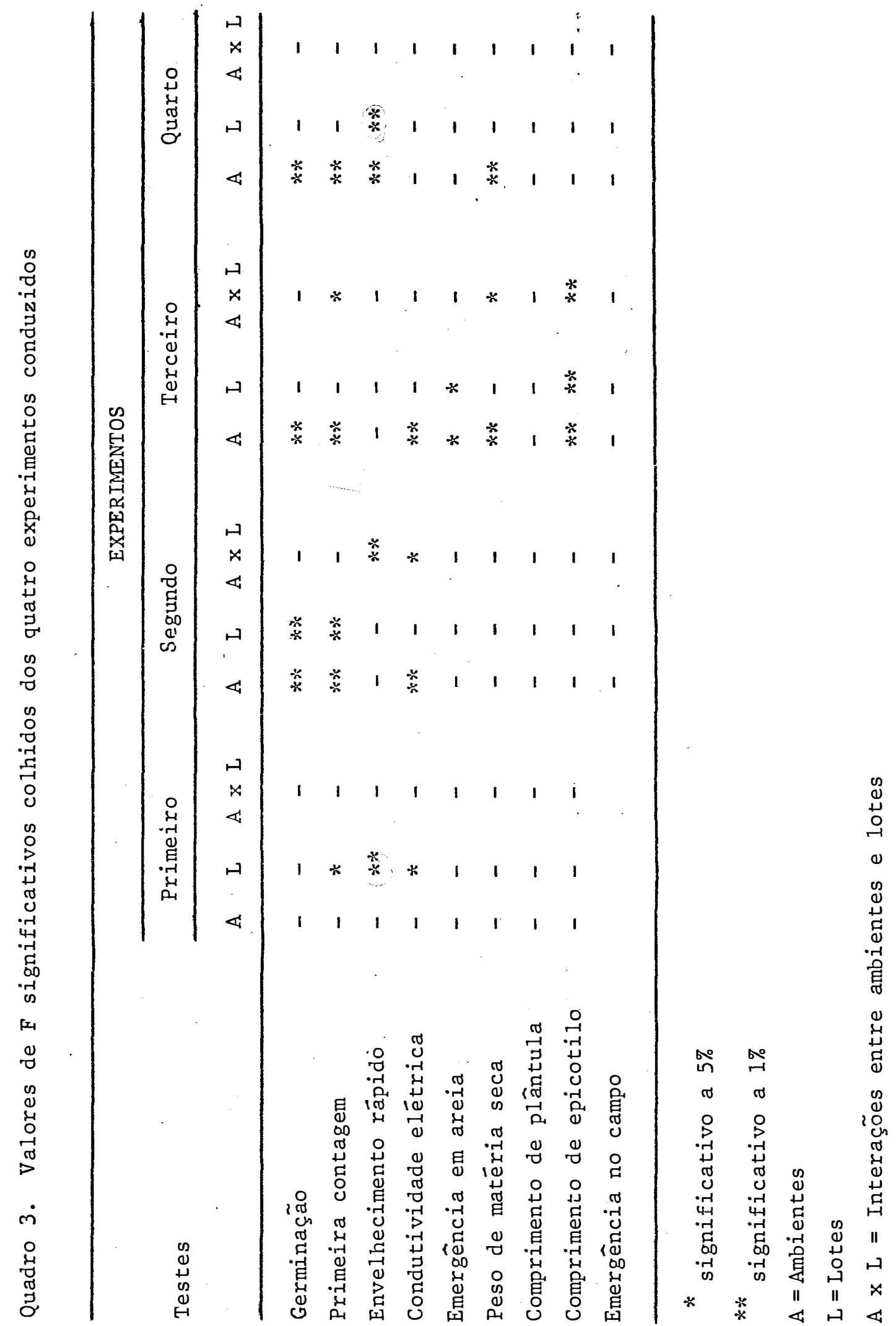


segundo. 0 envelhecimento räpido, por sua vez, também mostrou-se inconsistente ao revelar significância entre lotes no primeiro e último experimentos.

De um modo geral os demais testes foram menos sensíveis que os três mencionados.

Todavia os testes de germinação e primeira contagem acusa ram diferenças entre os ambientes de armazenagem ao longo do segundo, terceiro e quarto experimentos, fato este que nao se repetiu com os demais testes que apresentaram significância em poucos casos.

Estas considerações sobre o comportamento dos vários tes tes são de muita importância no estudo individual dos mesmos, que serä apresentado nos itens que seguem.

\subsection{Teste de Germinação.}

No quádro 4 se encontram as mëdias de germinação para cada lote durante os experimentos, a diferença mínima significativa entre lotes no segundo experimento e os coeficientes de variação observados.

Verifica-se que os lotes mantiveram a mesma germinação entre si ao longo de todos os experimentos, salvo no segundo, quando o lote três se mostrou de germinação inferior aos demais. Esta única variação estatística pode ser considerada com uma alteração ou falha que ocorre normalmente em série de ensaios de laboratório e portanto deve ser desprezada. 
Como as sementes de suja são consideradas, em gera1, como muito susceptíveis à armazenagem, acredita-se que os lotes que foram escolhidos ao acaso para a condução deste trabalho sejam muito semelhantes entre si, uma vez que a porcentagem de germinação dos mesmos permaneceu sem variações significativas durante o período em que foram realizados os experimentos.

Pelos dados apresentados no quadro 5 verifica-se que os ambientes exerceram influência sobre a germinação das sementes, porém não provocaram variação entre os lotes conforme exposto no parägrafo anterior. Alëm disso é interessante destacar que o ambiente natưral, ao conträrio do esperado, foi mais favorável para a manifestação da germinação das sementes. Este fato provavelmente é consequência das sementes provenientes da câmara seca não terem encontrado suprimento adequado de água no substrato de germinação para promover o desenvolvimento normal da plântula. E interessante todavia lembrar aqui que Mc DONALD Jr. (1977) e MARCOS FILHO et alii (1978) observaram, em testes de germinação, maior porcentagem e desenvolvimento das p.lântulas em sementes com teor de umidade mais elevado.

Destaca-se também que os coeficientes de variação dos ex perimentos são baixos mostrando que os ensaios foram conduzidos satisfatoriamente. 
Quadro 4. Germinação (dados transformados): médias observadas para lotes

\begin{tabular}{lcccc}
\hline \multirow{2}{*}{ Lotes } & \multicolumn{3}{c}{ EXPERIMENTOS } \\
\cline { 2 - 5 } & Primeiro & Segundo & Terceiro & Quarto \\
\hline 1 & 68,05 & 68,35 & 69,39 & 70,32 \\
3 & 66,50 & 68,76 & 68,89 & 67,31 \\
4 & 67,33 & 62,61 & 72,37 & 66,22 \\
5 & 68,05 & 70,21 & 73,80 & 69,23 \\
\hline D.M.S. (Tukey 5\%) & 66,89 & 70,75 & 69,88 & 66,68 \\
Entre lotes & - & & 6,87 & 6,65 \\
C.V. & 5,00 & 5,23 & - & \\
\hline
\end{tabular}

Quadro 5. Germinação (dados transformados): médias observadas para cada ambiente

\begin{tabular}{lccc}
\hline Experimentos & \multicolumn{2}{c}{ AMBIENTES } & $\begin{array}{c}\text { D.M.S. } \\
\text { (Tukey 5\%) }\end{array}$ \\
\cline { 2 - 4 } Câmara seca & Ambiente normal & - \\
Primeiro & 67,36 & 67,36 & 2,30 \\
Segundo & 65,74 & 70,53 & 3,14 \\
Terceiro & 67,93 & 73,80 & 2,92 \\
Quarto & 63,43 & 72,47 & \\
\hline
\end{tabular}




\subsection{Primeira Contagem de Germinação}

No quadro 6 encontram-se expressas as médias, as diferenças mínimas significativas do primeiro e segundo experimento, as médias referentes à interação ambientes x lotes com a diferença mínima significativa correspondente ao terceiro experimento e, também, os coeficientes de variação de cada experimento.

A primeira contagem do teste padrão de germinação, em geral, è considerada como um bom teste de vigor, por vários autores (EDJE \& BURRIS, 1970; BYRD \& DELOUCHE, 1971; POPINIGIS, 1977). Sendo assim, neste trabalho os dados da primeira contagem foram analisados separad amente.

No primeiro experimento a primeira contagem do lote dois foi significativamente inferior a do lote quatro, enquanto não houve diferenças entre os demais. Já no segundo experimento o lote três foi inferior aos lotes quatro e cinco não ocorrendo outras diferenças significativas. Em relação ao quarto experimento não foi observada variação estatística alguma.

Tendo em vista os coeficientes de variação (quadro 6) baixos, os dados obtidos são de alta confiabilidade motivo pelo qual considera-se que as diferenças encontradas não foram consistentes. Sendo assim, verificou-se, que o teste não detectou diferenças entre os 1otes. WE'TZEL (1975), trabalhando com tamanho e vigor de sementes de soja, encontrou diferenças significativas entre lotes utilizando este teste. 
Quanto a interação ambientes x lotes observada no terceiro experimento, é interessante destacar que o lote dois armazenado em câmara seca foi significativamente inferior ao lote quatro do mesmo ambiente como assim também significativamente inferior aos lotes armazenados em ambiente norma1. Por outro lado, os lotes um e cinco da câmara seca manifestaram-se significativamente inferiores ao lote dois do ambiente norma1. Como no caso de germinação, acredita-se que esta variação tenha sido causada principalmente pelo baixo teor de umidade das sementes armazenadas em câmara seca que impediu um melhor comportamento no teste.

No quadro 7 . se observa que a primeira contagem das sementes armazenadas em câmara seca foi inferior daquelas do ambiente nor ma1. Novamente julga-se que os resultados obtidos poderiam ser devido à diferença de teores de umidade existente entre as sementes no início do teste, conforme jā salientavam Mc DONALD Jr. (1977) e MARCOS FILHO et alii (1978). 
Quadro 6. Primeira contagem de germinação (dados transformados): médias observadas para lotes e para interação ambientes x lotes

\begin{tabular}{lcccc}
\hline \multirow{2}{*}{ Lotes } & \multicolumn{3}{c}{ EXPERIMENTOS } \\
\cline { 2 - 4 } & Primeiro & Segundo & Terceiro & Quarto \\
\hline 1 & 53,18 & 65,16 & 62,38 & 54,74 \\
2 & 50,24 & 65,71 & 62,61 & 56,22 \\
3 & 54,05 & 61,42 & 67,07 & 51,34 \\
4 & 55,89 & 69,02 & 67,58 & 53,84 \\
5 & 53,14 & 68,16 & 63,15 & 50,44 \\
\hline D.M.S. (Tukey 5\%) & & & & - \\
Entre lotes & 4,72 & 5,22 & - & 8,98 \\
C.V. & 6,12 & 5,47 & 7,75 & \\
\hline \hline
\end{tabular}

TERCEIRO EXPERIMENTO

Lotes

Câmara seca

Ambiente NormaI

\begin{tabular}{lll}
\hline 1 & 60,11 & 64,63 \\
2 & 52,05 & 73,17 \\
3 & 63,53 & 70,53 \\
4 & 65,72 & 69,43 \\
5 & 59,14 & 67,17 \\
\hline
\end{tabular}

D.M.S. (Tukey 5\%)

12,05

Quadro 7. Primeira contagem de germinação (dados transformados): mēdias observadas para cada ambiente

\begin{tabular}{lccc} 
Experimentos & \multicolumn{2}{c}{ AMBIENTES } & $\begin{array}{c}\text { D.M.S. } \\
\text { (Tukey 5\%) }\end{array}$ \\
\cline { 2 - 3 } & Câmara seca & Ambiente norma1 & - \\
\hline Primeiro & 53,30 & 53,30 & 2,33 \\
Segundo & 63,18 & 68,60 & 3,23 \\
Terceiro & 60,11 & 68,99 & 3,09 \\
Quarto & 47,26 & 59,37 & \\
\hline
\end{tabular}




\subsection{Envelhecimento Rāpido.}

No quadro 8 observam-se os dados referentes as médias obtidas para lotes, as diferenças mínimas significativas do primeiro e quarto experimentos e os coeficientes de variação correspondentes a cada experimento. Assim, tambēm se encontram as médias para a interação ambientes $x$ lotes do segundo experimento com a diferença mínima significativa.

DELOUCHE \& BASKIN (1973), EGLI et a $i$ i (1979) e USBERTI (1979) consideram o teste đe envelhecimento rápido como capaz de detectar diferenças entre lotes predizendo a capacidade de armazenamento. Os resultados obtidos neste trabalho não concordam com esses autores, já que o teste nä́o demonstrou ser consistente em todos os experimentos rea lizados.

As diferenças entre lotes foram observadas no primeiro e quarto experimentos. 0 lote três do primeiro experimento foi signi-ficativamente inferior aos demais e o lote cinco do quarto experimento foi inferior ao lote quatro sem demonstrar diferenças com os demais 1otes.

Com referência à interação ambientes x lotes observada no segundo experimento, o lote três da câmara seca mostrou-se significativamente inferior ao lote cinco do mesmo ambiente e ao lote dois do ambiente normal.

No quadro 9 pode-se verificar que somente no quarto experimento foi verificada diferença significativa entre ambientes, através 
Quadro 8. Envelhecimento räpido (dados transformados): médias observadas para lotes e para interação ambiente $x$ lotes

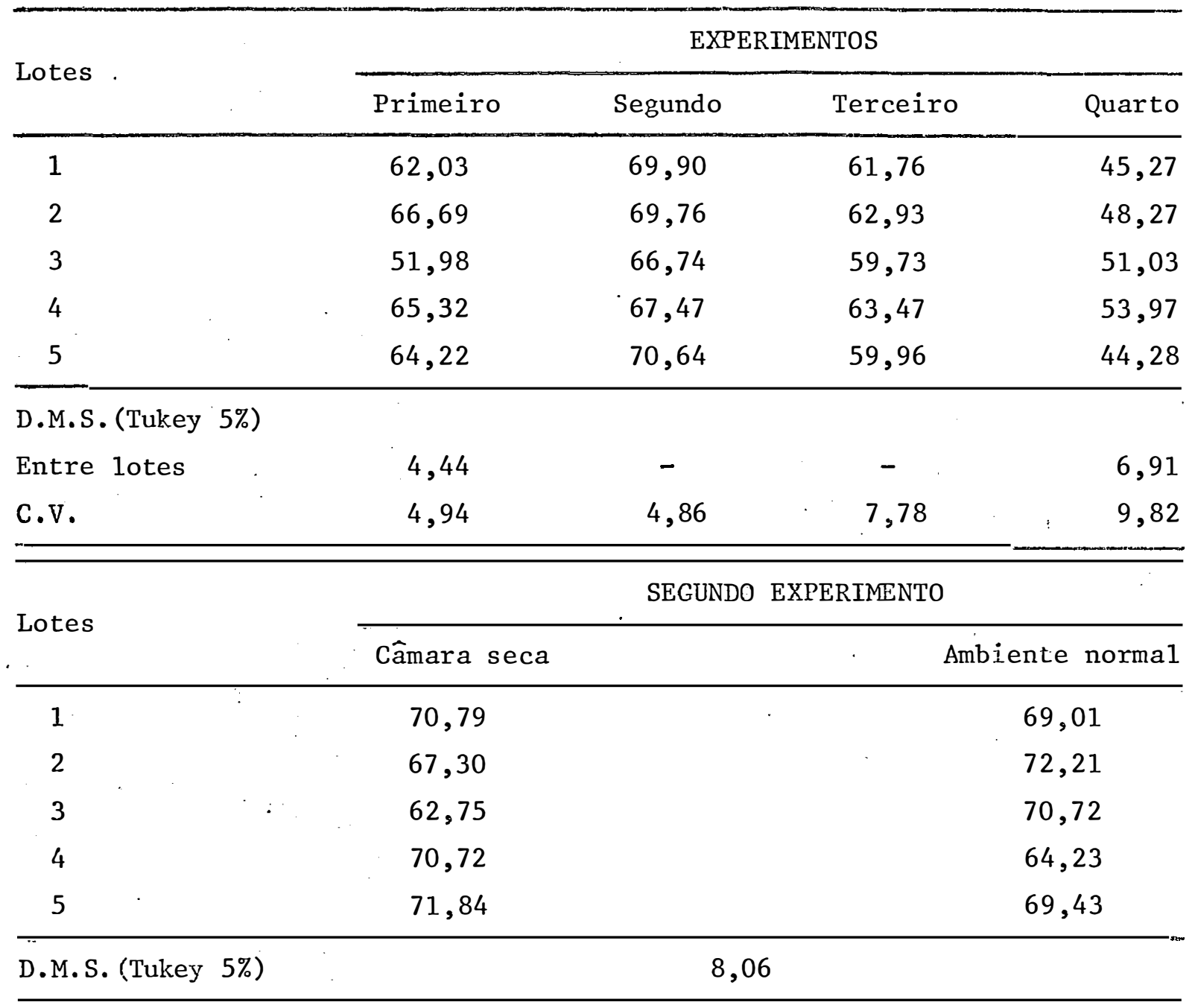

Quadro 9. Envelhecimento räpido (dados transformados): médias observadas para cada ambiente

\begin{tabular}{|c|c|c|c|c|}
\hline \multirow{2}{*}{ Experimentos } & & \multicolumn{2}{|c|}{ AMBIENTES } & \multirow{2}{*}{$\begin{array}{c}\text { D.M.S. } \\
\text { (Tukey } 5 \% \text { ) }\end{array}$} \\
\hline & & Câmara seca & Ambiente normal & \\
\hline Primeiro & . & 62,05 & 62,05 & - \\
\hline Segundo & & 68,68 & 69,12 & - \\
\hline Terceiro & & 61,57 & 61,57 & - \\
\hline Quarto & & 52,04 & 45,06 & 3,08 \\
\hline
\end{tabular}


do envelhecimento rápido.

As diferenças apontadas nos parágrafos anteriores, inclusive aquela encontrada no quarto experimento relacionada aos ambientes (quadro 9), estão coincidindo com as observações feitas por Mc DONALD Jr. (1977), TAO (1979) e MARCOS FIL.HO \& VINHA (1980) referentes ao problema de avaliação do teste de envelhecimento rápido quando o teor de umidade dos lotes é desuniforme. Além do exposto, considerando que os coeficientes de variação são baixos, os resultados obtidos neste teste não demonstram muita variabilidade, o qual indicaria que os lotes são semelhantes entre si.

\subsection{Condutividade Elétrica}

No quadro 10 observa-se as médias obtidas para lotes, a diferença mínima significativa do prímeiro experimento, os coeficientes de variação de cada experinento e as médias da interação ambientes $\mathrm{x}$ lotes do segundo experimento com a respectiva diferença minima significativa.

EDJE \& BURRIS (1970) e MARCOS FILHO et alii (1983) conceituam a condutividade elétrica como um dos testes, além de outros, de bom comportamento para determinar diferenças de vigor entre lotes de sementes de soja. No desenvolvimento do presente trabalho não se teve a oportunidade de constatar dito conceito, $j a$ que os resultados obtidos não demonstraram variações significativas ao longo dos experimentos, sal. vo no primeiro, onde nota-se que o lote dois é significativamente 
superior ao lote três mas sem diferir dos demais lotes.

A interação ambientes $x$ lotes (quadro 10) no segundo experimento revelou uma tendência do material armazenado em ambiente normal apresentar melhor comportamento que os lotes conservados em câmara seca, embora estatisticamente só os lotes três e quatro do ambiente normal fossem significativamente superiores a todos os da câmara seca e iguais aos lotes do mesmo ambiente. Da mesma forma o lote cinco do ambiente normal foi significativamente superior aos lotes três e cinco da câmara seca.

Como se pode observar o comportamento dos lotes ao longo dos experimentos não apresentou variações consistentes, com exceção das diferenças significativas mencionadas zcima, as quais poderiam ter sido ocasionadas por pequenas variantes não percebidas durante a execus são do teste, coincidindo desta forma com GILL \& DELOUCHE (1973) que acharam o.teste inconsistente por ser muito sensível a variados fato-res. Também MARCOS FIJHO et alii (1984) trabalhando com soja não obti veram resultados positivos com o teste de lixiviação de $\mathrm{K}$ que, segundo Simon e Raja-Harum (1972), citados por esses autores, proporciona as mesmas informações que o teste de condutividade elétrica.

No quadro 11 tem-se os dados referentes aos ambientes e pode-se observar, por meio das médias, que no segundo e terceiro experimentos o ambiente normal foi significativamente melhor que a câmara seca, não encontrando-se diferenças nos outros experimentos. 
Quadro 10. Condutividade elétrica (micro-mhos/grama): médias observadas para lotes e interação ambientes $x$ lotes

\begin{tabular}{|c|c|c|c|c|}
\hline \multirow{2}{*}{ Lotes } & \multicolumn{4}{|c|}{ EXPERIMENTOS } \\
\hline & Primeiro & Segundo & Terceiro & Quarto \\
\hline 1 & 69,11 & 72,78 & 67,70 & 76,70 \\
\hline 2 & 67,90 & 71,97 & 65,23 & 73,17 \\
\hline 3 & 78,69 & 68,22 & 69,98 & 69,72 \\
\hline 4 & 71,25 & 67,44 & 65,44 & 66,62 \\
\hline 5 & 70,71 & 70,69 & 66,09 & 72,59 \\
\hline \multicolumn{5}{|l|}{ D.M.S. (Tukey 5\%) } \\
\hline Entre lotes & 9,98 & - & - & - \\
\hline $\mathrm{C} . \mathrm{V}$. & 9,63 & 9,05 & 12,46 & 9,14 \\
\hline \multirow{2}{*}{ Lotes } & \multicolumn{4}{|c|}{ SEGUNDO EXPERIMENTO } \\
\hline & Câmara seca & $\therefore$ & $\therefore \quad A m b$ & normal \\
\hline 1 & 76,17 & \multirow{5}{*}{ : } & & \\
\hline 2 & 74,40 & & & \\
\hline 3 & 80,38 & & & \\
\hline 4 & 76,79 & & & \\
\hline 5 & 78,83 & & & \\
\hline D.M.S. (Tukey 5\%) & \multicolumn{4}{|c|}{$1.5,31$} \\
\hline
\end{tabular}

Quadro 11. Condutividade elétrica (micro-mhos\%grama): médias observadas para cada ambiente

\begin{tabular}{lccc}
\hline \multirow{2}{*}{ Experimentos } & \multicolumn{2}{c}{ AMBIENTES } & $\begin{array}{c}\text { D.M.S. } \\
\text { (Tukey 5\%) }\end{array}$ \\
\cline { 2 - 3 } & Câmara seća & Ambiente normal & - \\
\hline Primeiro & 71,53 & 71,53 & 4,10 \\
Segundo & 77,31 & 63,12 & 5,38 \\
Terceiro & 72,52 & 61,25 & - \\
Quarto & 71,17 & 72,35 & \\
\hline
\end{tabular}


As diferenças encontradas no quadro 11 podem estar relacionadas com as observações realizadas por TAO (1978) que trabalhando com soja constatou que as sementes com teor de umidade de $8,8 \%$, ou menor, possivelmente tenham mais facilidade de trincamento o qual aumen ta a condutividade elétrica. Desta forma concluiu que para o teste de condutividade elétrica deve-se trabalhar com teores de umidade mais elevados

\subsection{Emergência em Areia}

No quadro 12 encontram-se os dados correspondentes às médias entre lotes, a diferença mínima significativa do terceiro experimento e os coeficientes de variação de cada experimento.

Como pode-se observar o comportamento dos lotes nos experimentos desenvolvidos foi semelhante, a exceção do lote cinco que mostrou-se significativamente inferior ao quatro, sem revelar diferença com os demais.

No quadro 13, referente a ambientes, só no terceiro experimento a média do ambiente normal foi significativamente superior à média da câmara seca.

De um modo geral, a emergência foi satisfatória em todos os experimentos, conforme jā frizara RAZERA (1982). 
Quadro 12. Emergência em areia (dados transformados): médias observadas para lotes

\begin{tabular}{lcccc}
\hline & \multicolumn{4}{c}{ EXPERIMENTOS } \\
\cline { 2 - 5 } Lotes & Primeiro & Segundo & Terceiro & Quarto \\
\hline 1 & 64,22 & 68,07 & 61,89 & 74,19 \\
2 & 65,88 & 65,38 & 57,49 & 75,92 \\
3 & 59,36 & 65,80 & 59,09 & 75,48 \\
4 & 70,36 & 68,13 & 64,67 & 76,36 \\
5 & 68,08 & 69,57 & 53,97 & 71,49 \\
\hline D.M.S. (Tukey 5\%) & & & & - \\
Entre lotes & - & - & 9,48 & 5,21 \\
C.V. & 7,08 & 5,68 & 6,87 & $:$ \\
\hline
\end{tabular}

Quadro 13. Emergência em areia (dados transformados): médias observadas para cada ambiente

\begin{tabular}{|c|c|c|c|}
\hline \multirow{2}{*}{ Experimentos } & \multicolumn{2}{|c|}{ AMBIENTES } & \multirow{2}{*}{$\begin{array}{l}\text { D.M.S. } \\
\text { (Tukey } 5 \%)\end{array}$} \\
\hline & Câmara seca & Ambiente normel. & \\
\hline Primeiro & 65,58 & $6 \dot{5}, 58$ & - \\
\hline Segundo & 65,88 & 68,90 & - \\
\hline Terceiro & 56,60 & 62,25 & 4,06 \\
\hline Quarto & 74,86 & 74,52 & - \\
\hline
\end{tabular}


Segundo POPINIGIS (1977) o teste de emergência em areia é utilizado para detectar diferença de vigor entre lotes, o que não foi observado no presente trabalho, quiça, porque os lotes apresentem grande homogeneidade.

Embiora não tenha sido feita anālise estatística entre os experimentos é interessante destacar aqui, que no quarto experimento a emergência em areia aparentemente foi superior a dos demais experimentos. $\overline{\mathrm{E}}$ provável que este fato se deva às temperaturas reinantes na oca sião (mês de fevereiro de 1985).

\subsection{Peso de Matéria Seca da Parte Aérea da Plântula}

Observa-se no quadro 14 as médias obṭidas para lotes ao longo dos quatro experimentos com seus coeficientes de variação, assım também mostra-se as médias da interação ambientes x lotes con a diferença mínima significativa correspondente.

Pelos dados expostos no refierido quadro, pode--se observar que o teste de peso de matéria seca não acusou diferenças significativas entre lotes, não coincidindo desta forma com o exporto por POPINIGIS (1977). O único destaque foi observado na interação ambientes $\mathrm{x}$ lotes do terceiro experimento onde o.lote um conservado em câma-ra seca mostrou ser significativamente inferior ao lote três do ambiente normal e tendo o comportamento semelhante aos dernais lotes.

Com referência ao quadro 15 de ambientes, verificam-se diferenças significativas nos experimentos terceiro e quarto, como 
Quadro 14. Peso de matéria seca (miligramas/plântula): médias observadas para lotes e para interação ambientes $\mathrm{x}$ lotes

\begin{tabular}{|c|c|c|c|c|}
\hline \multirow{2}{*}{ Lotes } & \multicolumn{4}{|c|}{ EXPERIMENTOS } \\
\hline & Primeiro & Segundo & Terceiro & Quarto \\
\hline 1 & 35,83 & 47,52 & 45,94 & 51,14 \\
\hline 2 & 37,98 & 45,23 & 46,13 & 50,22 \\
\hline 3 & 36,46 & 43,20 & 48,41 & 48,87 \\
\hline 4 & 38,65 & 42,72 & 43,77 & 47,96 \\
\hline 5 & 36,55 & 46,58 & 48,25 & 47,01 \\
\hline $\mathrm{C} . \mathrm{V}$. & 5,34 & 7,21 & 5,28 & 4,72 \\
\hline \multirow{2}{*}{ Lotes } & \multicolumn{4}{|c|}{ TERCEIRO EXPERIMENTO } \\
\hline & \multicolumn{2}{|l|}{ Câmara seca } & \multicolumn{2}{|c|}{ Ambiente normal } \\
\hline 1 & 41,24 & . & \multicolumn{2}{|c|}{50,62} \\
\hline 2 & 43,84 & & \multicolumn{2}{|c|}{48,42} \\
\hline 3 & 42,76 & & \multicolumn{2}{|c|}{54,06} \\
\hline 4 & 42,70 & & \multicolumn{2}{|c|}{44,84} \\
\hline 5 & 48,91 & & \multicolumn{2}{|c|}{47,60} \\
\hline D.M.S. (Tukey 5\%) & \multicolumn{4}{|c|}{9,72} \\
\hline
\end{tabular}

Quadro 15. Peso de matéria seca (miligramas/p1ântuia): médias observadas para cada ambiente

\begin{tabular}{lccc}
\hline Experimentos & \multicolumn{2}{c}{ AMBIENTES } & $\begin{array}{c}\text { D.M.S. } \\
\text { (Tukey 5\%) }\end{array}$ \\
\cline { 2 - 3 } & Cämara seca & Ambiente normal & - \\
Primeiro & 37,09 & 37,09 & - \\
Segundo & 45,93 & 44,17 & 2,44 \\
Terceiro & 43,89 & 49,11 & 2,30 \\
Quarto & 46,88 & 51,19 & \\
\hline
\end{tabular}


ocorreu em outros testes discutidos nesta pesquisa, os resultados obtidos para ambiente normal foram superiores aos da câmara seca. Porém, neste caso, ê pouco provável que se deva ao teor de umidade inicial das sementes .

\subsection{Comprimento de P1ântula}

Pelos dados observados no quadro 16, onde se encontram as médias para lotes e os coeficientes de variação para cada experimento, pode-se observar que o teste de comprimento de plântula não revelou diferenças entre lotes, o qual estaria relacionado à semelhança de qualidade dos lotes, o que dificultaria a detecção.

Da mesma forma no quadro 17 não se observam diferenças significativas entre os ambientes, o que nao corrobora os resultados de McDONALD Jr. (1977) .

\subsection{Comprimento de Epicotilo}

No quadro 18 encontram-se os dados referentes às médias obtidas para loćes, os coeficientes de variạção de cada experimento, assım também as mẻdias da interação ambientes $\mathrm{x}$ lotes do terceiro experimento com a diferença mínima significativa correspondente.

A ausência de resposta ao teste foi observada :pelos resultados ao longo dos experimentos, a exceção da interação ambientes $\mathrm{x}$ lotes determinada no terceiro experimento, onde os lotes dois, três, quatro e cinco armazenados em ambiente normal foram significativamente inferiores ao lote um do mesmo ambiente e a todos os lotes 
Quadro 16. Comprimento de plântula $(\mathrm{cm})$ : médias observadas para lotes

\begin{tabular}{ccccr}
\hline \multirow{2}{*}{ Lotes } & \multicolumn{4}{c}{ EXPERIMENTOS } \\
\cline { 2 - 4 } & Primeiro & Segundo & Terceiro & Quarto \\
\hline 1 & 18,71 & 23,50 & 24,40 & 25,85 \\
2 & 18,61 & 23,94 & 22,55 & 25,36 \\
3 & 17,90 & 24,56 & 22,56 & 25,94 \\
4 & 18,33 & 23,50 & 24,09 & 24,43 \\
5 & 19,46 & 23,16 & 23,13 & 25,04 \\
\hline C.V. & 6,24 & 5,67 & 6,46 & 3,82 \\
\hline
\end{tabular}

Quadro 17. Comprimento de plântula (cm): médias'observadas para ambientes

\begin{tabular}{|c|c|c|}
\hline \multirow{2}{*}{ Experimentos } & \multicolumn{2}{|c|}{ AMBIENTES } \\
\hline & Câmara seca & Ambiente normal \\
\hline Primeiro & 18,60 & 18,60 \\
\hline Segundo & 24,17 & 23,29 \\
\hline Terceiro & 23,80 & 22,89 \\
\hline Quarto & 25,31 & 25,34 \\
\hline
\end{tabular}


conservados em câmara seca. Embora CARVALHO et alii (1977), trabalhando com soja, tenham observado que o teste de comprimento de epicotilo teve um comportamento eficiente para determinar qualidade de sementes, os resultados obtidos no presente trạalho não concordam com o mesmo.

Nas médias de ambientes observadas no quadro 19, sỏ no terceiro experimento detectou-se que as sementes da câmara seca tiveram um desenvolvimento significativamente melhor que as de ambiente nor mal. Este fato, diante dos demais resultados, não apresenta maior importância e deve ser considerado com uma variação anormal.

\subsection{Emergência no Campo}

As médias para lotes e os coeficientes de variação que correspondem a cada experimento encontram-se no quadro 20. Da mesma for ma as médias para ambientes são observadas no quadro 21 .

Como se pode notar nos quadros mencionados, não se verificaram diferenças de comportamento entre lotes, nem entre ambientes ao longo dos experimentos realizados, o que mostra que no presente trabalho não se confirma o salientado por MARCOS FILHO et alii (1984) que trabalhando com soja observaram que o teste de emergência no campo foi eficaz para apontar diferenças de qualidade entre lotes. Pode-se novamente aventar a possibilidade dos lotes serem muito semelhantes entre si. 
Quadro 18. Comprimento de epicotilo (cm): nédias observadas para lotes e para interação ambientes $\mathrm{x}$ lotes

\begin{tabular}{ccccc}
\hline \multirow{2}{*}{ Lotes } & \multicolumn{4}{c}{ EXPERIMENTOS } \\
\cline { 2 - 5 } & Primeiro & Segundo & Terceiro & Quarto \\
\hline 1 & 7,19 & 13,67 & 14,84 & 15,35 \\
2 & 6,83 & 13,61 & 11,79 & 15,39 \\
3 & 6,41 & 14,20 & 11,93 & 15,86 \\
4 & 6,85 & 13,40 & 11,96 & 14,65 \\
5 & 7,33 & 13,07 & 11,48 & 15,18 \\
\hline C.V. & 9,40 & 9,58 & 3,64 & 4,14 \\
\hline
\end{tabular}

TERCEIRO EXPERIMENTO

Lotes

\begin{tabular}{cc}
\hline Câmara seca & Ambiente normal \\
\hline 14,63 & 15,05 \\
15,13 & 8,46 \\
14,59 & 9,27 \\
14,20 & 9,72 \\
13,93 & 9,04
\end{tabular}

D.M.S. (Tukey 5\%)

1,79

Quadro 19. Comprimento de epicotilo $(\mathrm{cm}):$ médias observadas para čada ambiente

\begin{tabular}{lccc}
\hline \multirow{2}{*}{ Experimentos } & \multicolumn{2}{c}{ AMBIENTES } & $\begin{array}{c}\text { D.M.S } \\
\text { (Tukey 5\%) }\end{array}$ \\
\cline { 2 - 4 } & Câmara seca & Ambiente normal & - \\
\hline Primeiro & 6,92 & 6,92 & - \\
Segundo & 13,98 & 13,19 & 0,45 \\
Terceiro & 14,49 & 10,30 & - \\
Quarto & 15,42 & 15,15 & \\
\hline
\end{tabular}


Quadro 20. Emergência no campo (dados transformados): médias observadas para lotes

\begin{tabular}{ccccc}
\hline \multirow{2}{*}{ Lotes } & \multicolumn{4}{c}{ EXPERIMENTOS } \\
\cline { 2 - 5 } & Primeiro & Segundo & Terceiro & Quarto \\
\hline 1 & - & 41,79 & 58,10 & 58,48 \\
2 & - & 48,78 & 56,93 & 60,33 \\
3 & - & 48,29 & 57,94 & 60,45 \\
4 & - & 50,58 & 58,41 & 62,14 \\
5 & - & 52,45 & 56,77 & 58,39 \\
\hline C.V. & - & 14,74 & 17,79 & 8,31 \\
\hline
\end{tabular}

Quadro 21. Emergência no campo (dados transformados): mëdias observadas para cada ambiente

\begin{tabular}{lccc}
\hline \multirow{2}{*}{ Experimentós } & \multicolumn{3}{c}{ AMBIENTES } \\
\cline { 2 - 4 } & Câmara seca & Ambiente normal \\
\hline & & - & - \\
Primeiro & $\ddots$ & 48,70 & 48,05 \\
Segundo & 58,33 & 56,93 \\
Terceiro & 60,52 & 59,39 \\
Quarto & & \\
\hline
\end{tabular}




\subsection{Considerações Gerais.}

Conforme foi salientado por Delouche \& Cadwe1 (1960), cị tados por TOLEDO \& MARCOS FILHO (1977), para se chegar a conclusões mais seguras em trabalhos de pesquisa sobre tecnologia de sementes, deve-se incluir informações colhidas de testes de vigor, além do teste de germinação.

Assim o presente trabalho teve como principal objetivo verificar quais dos testes de vigor, aqui usados, seriam os mais eficientes para avaliar o desempenho de lotes de soja.em armazenamento.

Como ficou evidenciado nos diversos itens discutidos nes te capítulo, os resultados obtidos neste trabalho não permitiram a escolha de um ou mais testes a fim de se atingir o objetivo visado.

Ficou, todavia, bastante claro o fato dos lotes testados se apresentarem muito homogêneos entre si e de alta qualidade, revelando ótima conservação no armazenamento. Provavelmente a continuação do. emprego dos testes nesse material deverà revelar resultados de interesse e valor. 
5. CONCLUSÕES

A análise estatística dos dados e a interpretação dos resultados permitiram que se chegasse às seguintes conclusões:

a. Os testes aplicados sobre as sementes de soja nao detectaram possíveis diferençà fisiológicas entre os distintos lotes.

b. As sementes armazenadas em ambiente normal mostraram desempenho superior àquelas conservadas em câmara seca na maioria doṣ testes.

c) Os lotes utilizados para a realização desta pesquisa se mostraram possuidores de boas características fisiológicas e muito homogêneos entṛe si.

d) Concluiu-se, tambēm, em função dos dados obtidos, que será de grande importância dar continuidade a obtenção de dados com o material utilizado neste trabalho. 
BRASIL, MINISTÉRIO DA AGRICULTURA, 1976. Regras para Anälise de Sementes. Brasília. Divisão de Sementes e Mudas. 188p.

BYRD, H.W. e J.C.DELOUCHE, 1971. Deterioration of soybean seed in storage. Proc.Assoc.Off.Seed Anal. 61:41-47.

CARVALHO, N.M.; J.R.da SILVA e R.R. FALEIROS, 1977. Influência da origem sobre a qualidade fisiológica de sementes de soja (Glycine max (L.) Merri11) do cultivar "Santa Rosa". Cientifica, 5(1):35-39.

DELOUCHE, J.C. e C.C. BASKIN, 1973. Accelerated aging techniques for predicting the relative storability of seeds lots. Seed Science and Technology. 1(2):427-453.

EDJE, O.T. e J.S.BURRIS, 1970. Seedling vigor in soybeans. Proc.Assoc. Off.Seed Anal. 60:147-157. 
EGLI, D.B.; G.M.WHITE e D.M.TEKRONY, 1979. "Relationship betwen seed vigor and storability of soybean seed. J.Seed Technology. 3(2):1-11.

GILL, N.S. e J.C. DELOUCHE, 1973. Deterioration of seed corn during storage. Procc.Assoc.Off.Seed Anal. 63:33-50.

MARCOS FILHO, J.; M.C.B.FONSECA e M.A.MAZZOTTI, 1978, Teor de umidade da semente e comportamento da soja no teste de envelhecimento rápido. Pesq.Agropec.Bras.: Brasília, 13(3):11-16.

MARCOS FILHO, J. e J.L.VINHA, 1980. Teor de umidade da semente, condições de armazenamento e comportamento da soja (Glycine max (L.) Merril) no teste de envelhecimento rápido. O Solo, 72(1):21-26. Piracicaba, SP.

MARCOS FILHO, J.; S.M.CICERO e F.F.de TOLEDO, 1983. Manual de Anālise de Sementes. Piracicaba, SP. 3르 Ed, 112p.

MARCOS FILHO, J.; H.M.C.PESCARIN; Y.H.KOMATSU; C.G.B.DEMETRIO e A. FANCELLI, 1984. Testes para avaliação do vigor de sementes de soja e suas relações com a emergência das plântulas em campo. Pesq.Agropec. Bras. Brasília, 19(5):605-613.

McDONALD Ir., M.B., 1977. The influence of seed moisture on the accelerated aging seed vigor test. J. Seed Technol. 2(1):18-28. 
PIMENTEL GOMES, F., 1982. Curso de Estatística Experimenta1. 10 a $\quad$ Ed. Piracicaba, Escola Superior de Agricultura "Luiz de Queiroz". 430p.

POPINIGIS, I., 1977. Fisiologia da Semente. Ministério da Agricultura - AGIPLAN, 289p .

RAZERA, L.F., 1982. Emergençe of soybean (Glycine max (I..) Merri1) seed of various levels of soil temperature and moisture. Mississippi State University. Mississippi, 83p. (Tese de Ph.D.) .

TAO, K.J., 1978. Factors causıng variations in the condutivity test for soybean seeds. J.Seed Technol. 3(1):10-17.

TAO, K.J., 1979. An evaluation of alternative methods of accelerated aging seed vigor test for soybeans. J. Seed Technol.' 3(2):30-40.

TOLEDO, F.F.e J.MARCOS FILHO, 1977. Manual das Sementes, Tecnologia da Produção. Ed.Ceres - SP. 224P.

TOLEDO, F.F., 1981. Uso da estatística na pesquisa em sementes. Revis-ta Brasileira de Sementes. Brasília 3(2):65-77.

USBERTI, R., 1979. Determinação do potencial de armazenamento de sementes de soja pelo teste de envelhecimento acelerado. Revista Brasileira de Sementes, 1(2):28-40. 
WETZEL, C.T., 1975. Some effects of seed size on performance of soybeans (GLycine $\max ($ L.) Merri11). Mississippi State University. Mississippi. 117p. (Tese de Ph.D.). 
$A P \widehat{E} N D I C E$ 
Tabela 1. Teor de umidade (\%): médias observadas para lotes em cada ambiente

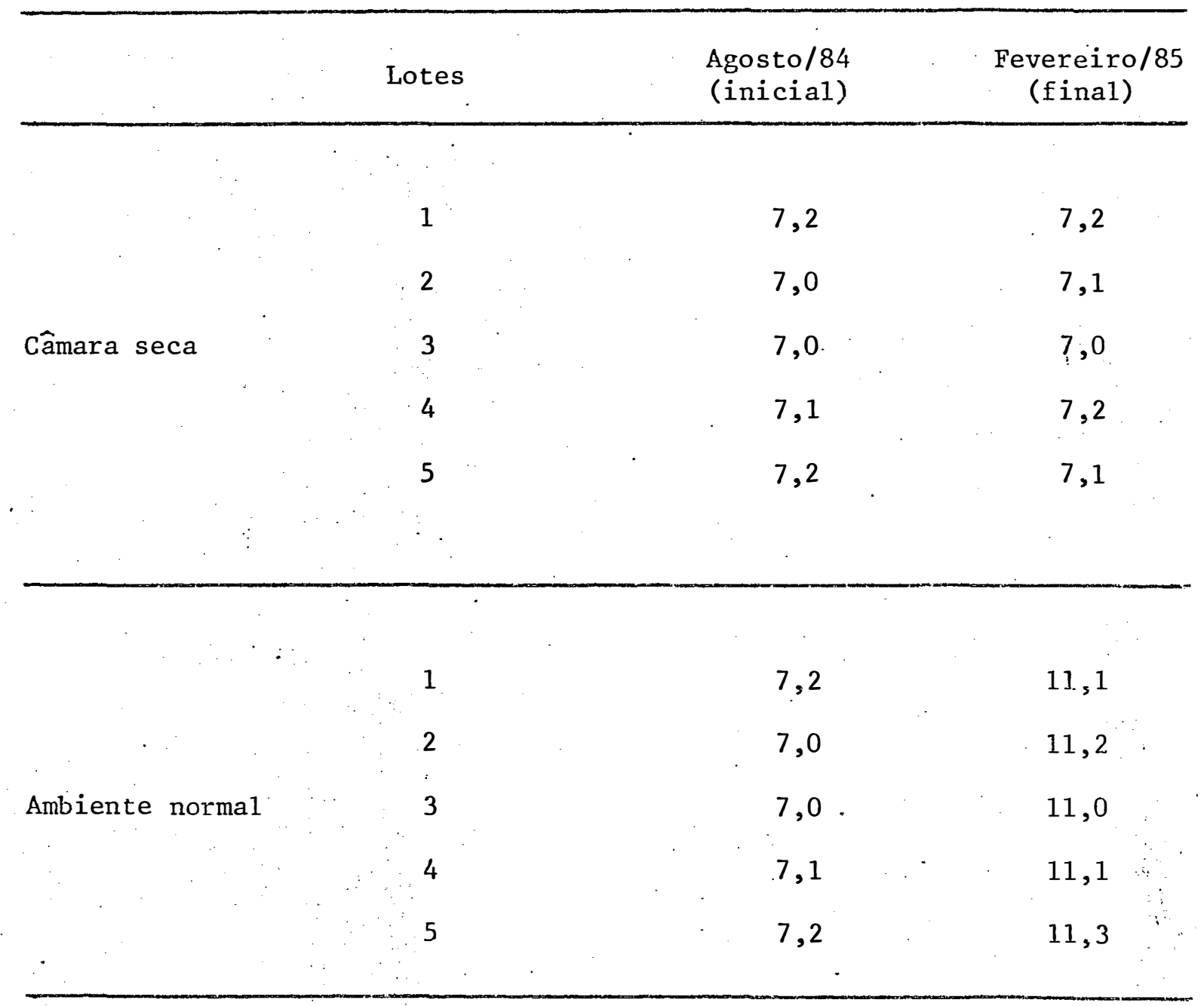


Tabela 2. Germinação (porcentagem): médias observadas para lotes em cada ambiente

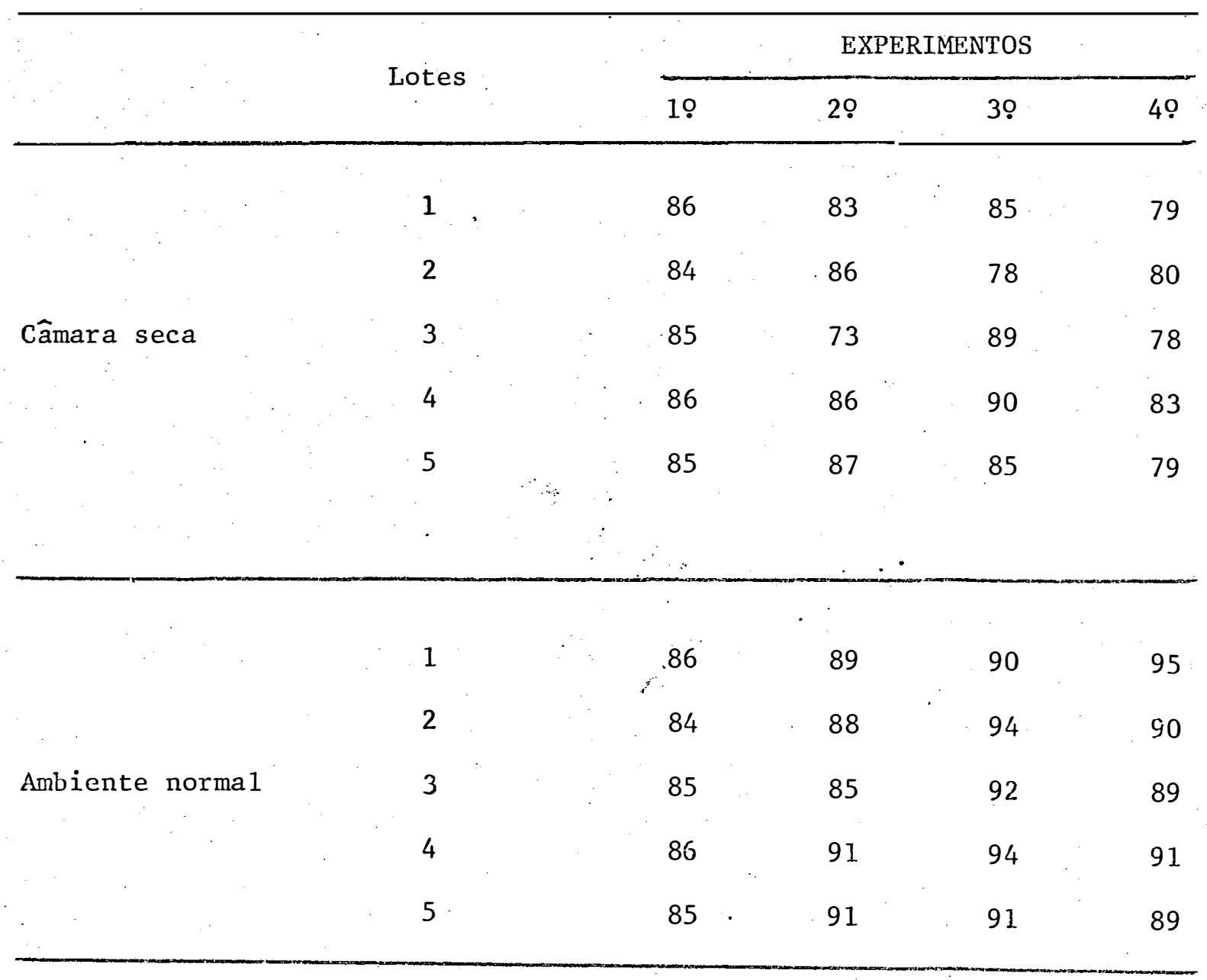


Tabeia 3. Primeira contagem (porcentagem): médias observadas para lotes em cada ambiente

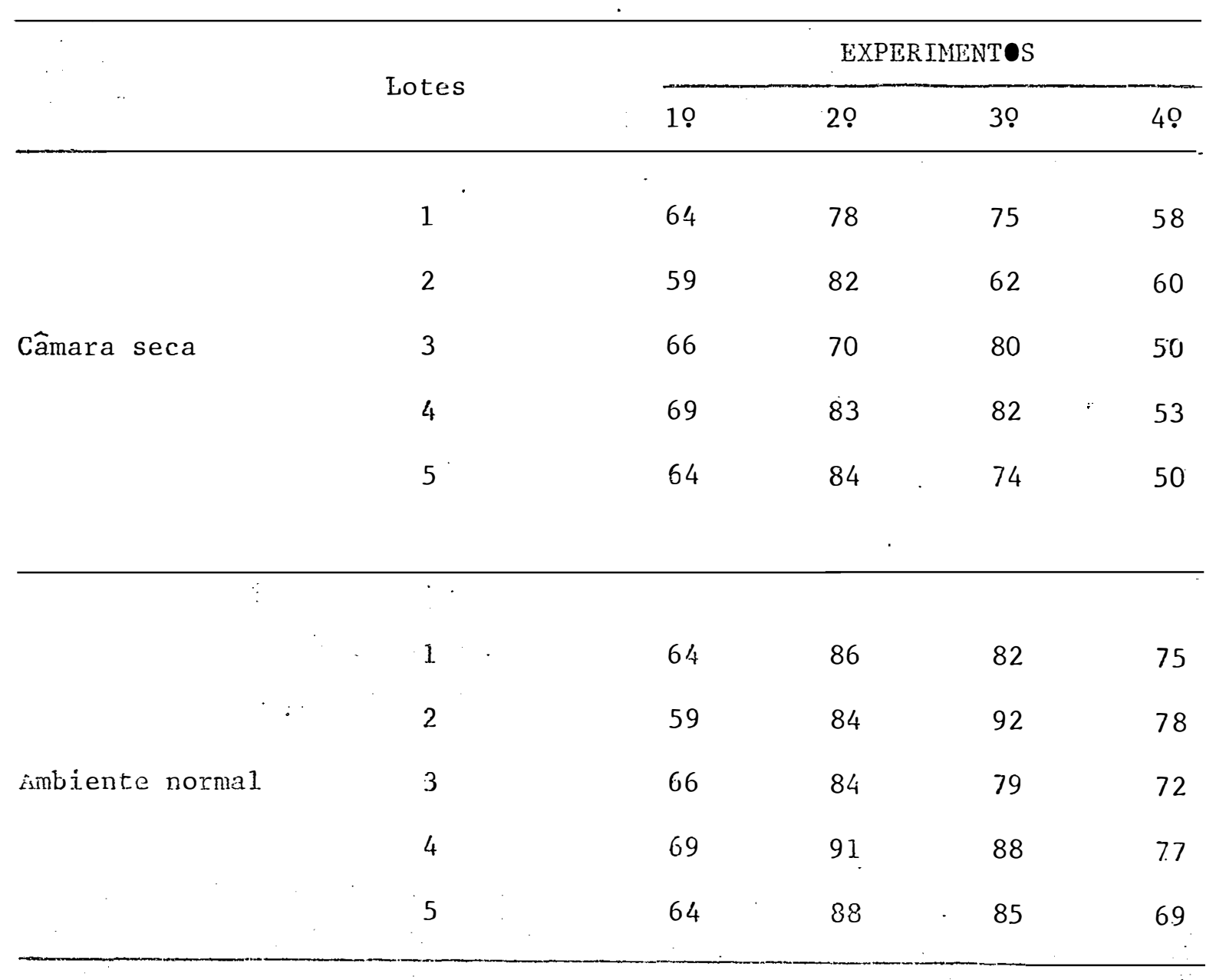


Tabela 4. Envælhecimento rápido (porcentagem): mëdias observadas para lotes e.n cada ambiente

\begin{tabular}{|c|c|c|c|c|c|}
\hline & \multirow{2}{*}{ Lotes } & \multicolumn{4}{|c|}{ EXPERIMENTOS } \\
\hline & & 10 & 29 & 39 & 40 \\
\hline \multirow{5}{*}{ Câmara seca } & 1 & 78 & 89 & 80 & 52 \\
\hline & 2 & 84 & 85 & 81 & 62 \\
\hline & 3 & 62 & 79 & 73 & 69 \\
\hline & 4 & 83 & 89 & 80 & 69 \\
\hline & 5 & 81 & 90 & 72 & 60 \\
\hline \multirow{5}{*}{ Ambiente normal } & 1 & 78 & 87 & 75 & 50 \\
\hline & 2. & 84 & 91 & 78 & 50 \\
\hline & 3 & 62 & 89 & 76 & 52 \\
\hline & 4 & 83 & 81 & 80 & 62 \\
\hline & 5 & 81 & 88 & 78 & 38 \\
\hline
\end{tabular}


Tabela 5. Emergência em areia (porcentagem): médias observadas para 1o-tes em cada época

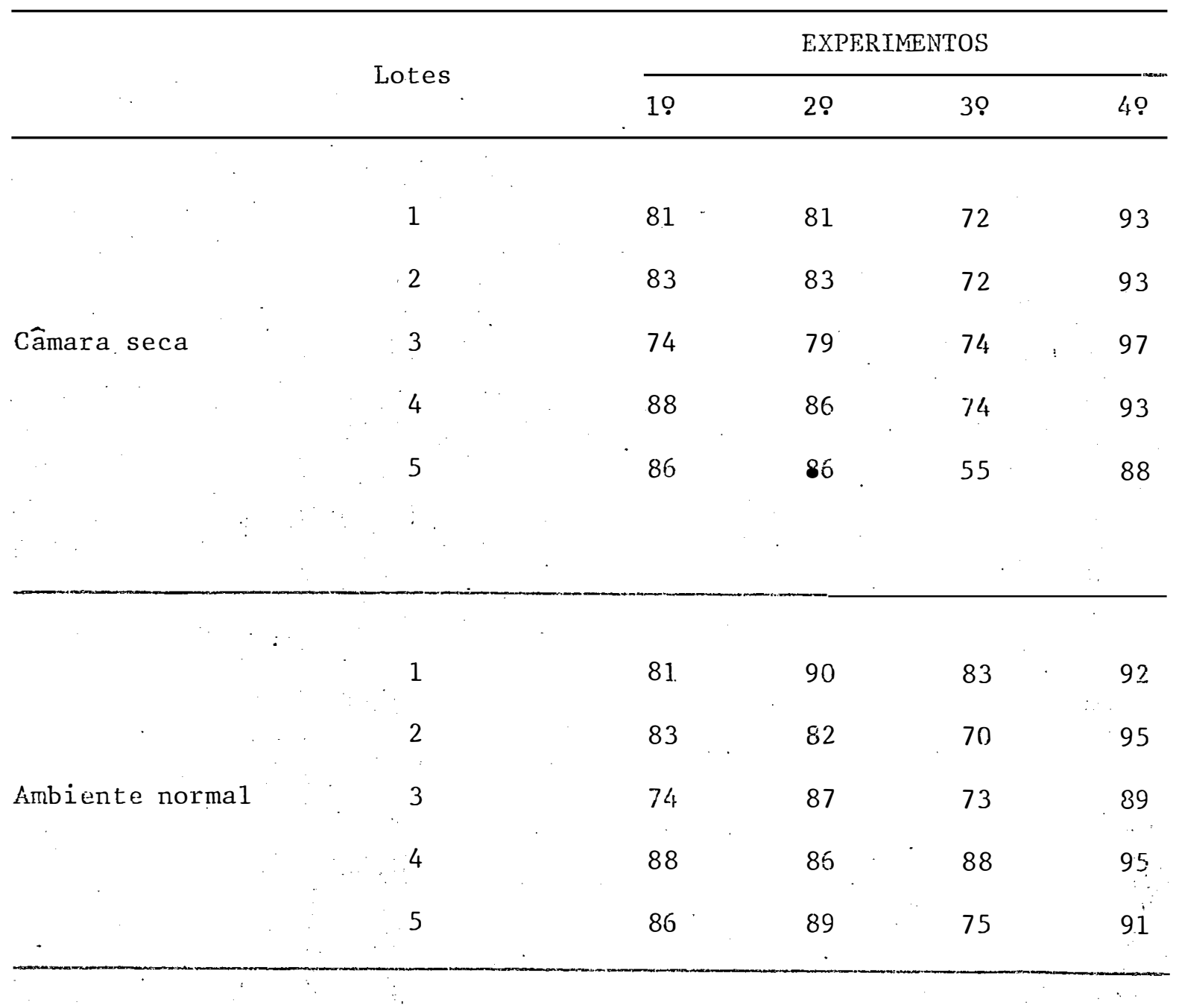


Tabela 6. Emergência no campo (porcentagem): médias observadas para 1otes em cada ambiente

\begin{tabular}{|c|c|c|c|c|c|}
\hline & \multirow{2}{*}{ Lotes } & \multicolumn{4}{|c|}{ EXPERTMENTOS } \\
\hline & & 19 & 29 & 39 & 49 \\
\hline \multirow{5}{*}{ Câmara seca } & 1 & - & 44 & 67 & 73 \\
\hline & 2 & - & 58 & 75 & 78 \\
\hline & 3 & - & 56 & 69 & 78 \\
\hline & 4 & - & 63 & 74 & 78 \\
\hline & 5 & - & 61 & 72 & 71 \\
\hline \multirow[t]{3}{*}{ - } & & & & & \\
\hline & 1 & - & 46 & 74 & 73 \\
\hline & 2 & - & 56 & 63 & 72 \\
\hline \multirow[t]{3}{*}{ Ambiente normal. } & 3 & - & 55 & 73 & 74 \\
\hline & 4 & - & 56 & 69 & 78 \\
\hline & 5 & - & 64 & 67 & 74 \\
\hline
\end{tabular}

